\title{
Integrated motivational interviewing and cognitive behaviour therapy can increase physical activity and improve health of adult ambulatory care patients in a regional hospital: the Healthy4U randomised controlled trial
}

Stephen Barrett ${ }^{1}$, Stephen Begg ${ }^{1}$, Paul O'Halloran ${ }^{2}$ and Michael Kingsley ${ }^{1 *}$ (i)

\begin{abstract}
Background: The aim of this study was to determine whether a twelve-week, health coaching intervention could result in changes in physical activity, anthropometrics and health-related outcomes in adults presenting to an ambulatory hospital clinic.

Methods: Seventy-two participants who reported being insufficiently active were recruited from an ambulatory hospital clinic and randomised to an intervention group that received an education session and eight 30-min telephone sessions of integrated motivational interviewing and cognitive behaviour therapy (MI-CBT), or to a control group that received the education session only. ActiGraph GT3X accelerometers were used to measure moderate-to-vigorous physical activity at baseline, post-intervention (3-months) and follow-up (6-months). Secondary outcome measures (anthropometrics, physical activity self-efficacy, health-related quality of life, type 2 diabetes risk) were also assessed at the three time points.

Results: At baseline, the mean age and body mass index of participants ( $n=72,75 \%$ females) were $53 \pm 8$ years and $30.8 \pm 4.1 \mathrm{~kg} / \mathrm{m}^{2}$, respectively. Treatment group influenced the pattern of physical activity over time $(p<0.001)$. The intervention group increased moderate-to-vigorous physical activity from baseline to post-intervention and remained elevated at follow-up by $12.9 \mathrm{~min} /$ day $(95 \% \mathrm{Cl}$ : 6.5 to $19.5 \mathrm{~min} /$ day). In contrast, at follow-up the control group decreased moderate-to-vigorous physical activity by $9.9 \mathrm{~min} /$ day $(95 \% \mathrm{Cl}:-3.7$ to $-16.0 \mathrm{~min} /$ day). Relative to control, at follow-up the intervention group exhibited beneficial changes in body mass $(p<0.001)$, waist circumference $(p<0.001)$, body mass index $(p<0.001)$, physical activity self-efficacy $(p<0.001)$, type 2 diabetes risk $(p<0.001)$, and health-related quality of life $(p<0.001)$.
\end{abstract}

Conclusions: This study demonstrates that a low contact coaching intervention results in beneficial changes in physical activity, anthropometrics and health-related outcomes that were maintained at follow-up in adults who report being insufficiently active to an ambulatory care clinic.

Trial registration: ANZCTR: ACTRN12616001331426. Registered 23 September 2016,

Keywords: Health promotion, Secondary prevention, Self-efficacy, Type 2 diabetes, Quality of life

\footnotetext{
* Correspondence: M.Kingsley@latrobe.edu.au

'La Trobe University, La Trobe Rural Health School, PO Box 199, Bendigo, VIC

3552, Australia

Full list of author information is available at the end of the article
}

(c) The Author(s). 2018 Open Access This article is distributed under the terms of the Creative Commons Attribution 4.0 International License (http://creativecommons.org/licenses/by/4.0/), which permits unrestricted use, distribution, and reproduction in any medium, provided you give appropriate credit to the original author(s) and the source, provide a link to the Creative Commons license, and indicate if changes were made. The Creative Commons Public Domain Dedication waiver (http://creativecommons.org/publicdomain/zero/1.0/) applies to the data made available in this article, unless otherwise stated. 


\section{Background}

Chronic diseases such as obesity, type 2 diabetes, and cardiovascular disease are prevalent, costly and largely preventable health conditions [1]. Almost 40\% of preventable hospital admissions are due to chronic disease [2]. While the primary role of hospitals is in medical diagnosis and treatment, the increasing prevalence of chronic diseases necessitates that preventative health is included in the scope of practice for many hospital services [3]. Hospitals are important settings in which to offer health promotion interventions, particularly when delivered opportunistically alongside the provision of secondary care [3]. Hospitals provide secondary care through the delivery of non-admitted medical consultations in specialities such as general surgery, orthopaedic surgery and endocrinology. A referral from a general practitioner (GP) is required to attend a hospital specialist clinic. Patients attending secondary care hospital clinics are $40 \%$ more likely than the general population to have one or more chronic disease [2]. Therefore, hospitals offer an advantage for health promotion beyond other settings as patients experiencing ill-health are more sensitive to behaviour change contemplation, and show increased responsiveness to health advice [4]. Patients have suggested that they would like, and to an extent expect the healthcare system to provide guidance on lifestyle behaviour change and physical activity (PA) [5]. Despite the evidence-base underlining the effectiveness of health promotion services in hospitals, preventative health options for increasing self-management or lifestyle counselling around PA have been notably distant from secondary care [6].

Regular PA plays a key role in both primary prevention and management of chronic diseases [7-10]. A dose-response relationship appears to exist for PA, such that individuals with the highest levels of physical activity are at lowest risk of chronic disease [11]. Challenges remain in the translation of established research findings on the health benefits of PA into practical everyday use in the health care system [12]. Interventions that deliver prescriptive exercises can increase PA levels in hospital patients [13]; however, PA maintenance over the longer term period has proven more difficult to achieve, with more than $50 \%$ of individuals that begin an exercise program dropping out or relapsing [14]. As a result, there is an increasing use of non-traditional methods of intervention delivery to influence health behaviour change and maintenance [15].

Motivational interviewing (MI) is a behaviour change technique demonstrated to be effective in overcoming ambivalence about behaviour change [16]. MI is a person-centered, goal-orientated method of guiding participants to elicit and strengthen personal motivation and commitment to change [16]. The collaborative nature between practitioner and client contrasts $\mathrm{MI}$ to more prescriptive, expert-driven interventions [17]. As MI was developed to increase motivation for initial behaviour change, it has been recommended to integrate action-orientated treatments (e.g., behavioural counselling, goal-orientated therapy, cognitive behaviour therapy) to build maintenance skills [16]. A meta-analysis indicated that MI was more effective and longer-lasting when combined with another active treatment [18]. Cognitive behaviour therapy (CBT) has been increasingly integrated with MI for behaviour change $[19,20]$. CBT strategies, including, but not limited to barrier identification, problem solving and self-monitoring are more goal-orientated and are used to address behaviour change across multiple health behaviour domains [19]. Integrating the theoretical underpinnings of $\mathrm{MI}$ and $\mathrm{CBT}$ together is theorised to promote long-lasting, sustained behaviour change [20]. Combined MI and CBT (MI-CBT) has resulted in small increases in PA [21-23]. Changes in PA were, however, the primary outcome in only one study [22], and all studies used self-reported outcome measures for PA change [21-23]. Self-reported measures for PA are shown to over-estimate activity when compared to objective measurement [24]. Furthermore, none of the studies recruited from outpatient secondary care clinics, where rates of chronic disease are known to be higher than the general population [25].

Hospitals are important settings from which to advocate for PA as a regular treatment for many of the lifestyle related risk factors and diseases [26]. Although doctors practicing in hospitals have stated that they do not have sufficient time to spend with patients giving advice on preventive measures [27], brief interventions in the hospital setting, such as recommendations to increase PA from clinical specialists, can have a strong effect on subsequent lifestyle choices by patients [26]. The Healthy4U intervention is an augmentation of service, where clinicians under time constraints can direct patients who might benefit from a health behaviour change intervention. This pathway offers a potential method to deliver a preventative health intervention to patients receiving secondary care, permitting hospital specialist to refer patients to a specific service tailored for them. To the best of our knowledge the Healthy4U study is the first study to examine the change and maintenance of behavioural and physiological outcomes following the integration of a behaviour change intervention into routine care for secondary care patients.

The primary aim of the Healthy4U study was to examine the effectiveness of integrated MI-CBT for change and maintenance of physical activity in insufficiently active patients presenting to an ambulatory outpatient clinic in a public hospital. Additionally, this study investigated the effectiveness of integrated MI-CBT for changes and maintenance in anthropometry, physical activity self-efficacy, type 2 diabetes risk, health related quality of life in this population. 


\section{Methods}

\section{Design}

The Healthy4U study was a single-blind randomised controlled trial designed and reported in line with the CONSORT recommendations for reporting (Fig. 1) [28]. The trial was registered with the Australian and New Zealand Clinical Trials Registry (ACTRN12616001331426) prior to patient recruitment.

\section{Participants}

Participants were recruited from an ambulatory, secondary care clinic in a major tertiary hospital in regional Victoria. These outpatients receive medical care from specialities in general surgery, orthopaedic surgery and endocrinology after a referral from a GP. Throughout the recruitment phase of the study, recruitment flyers were available at the clinic and patients who were potentially interested in participating made direct contact with the research team using information provided on the flyer.

Participants were included if they were between 18 and 69 years, and reported being insufficiently physically active, defined as obtaining less than $150 \mathrm{~min} /$ week of moderate-to-vigorous physical activity (MVPA) [29]. A single item question "As a rule, do you do at least half an hour of moderate or vigorous exercise (such as walking or a sport) on five or more days of the week?" - was used to identify insufficiently physically active individuals [30]. The following exclusion criteria were applied: sufficiently physically active [29]; an existing medical condition that contraindicated PA (indicated by the Physical Activity Readiness Questionnaire); a diagnosis of diabetes; deaf/hearing impaired; disabling neurological

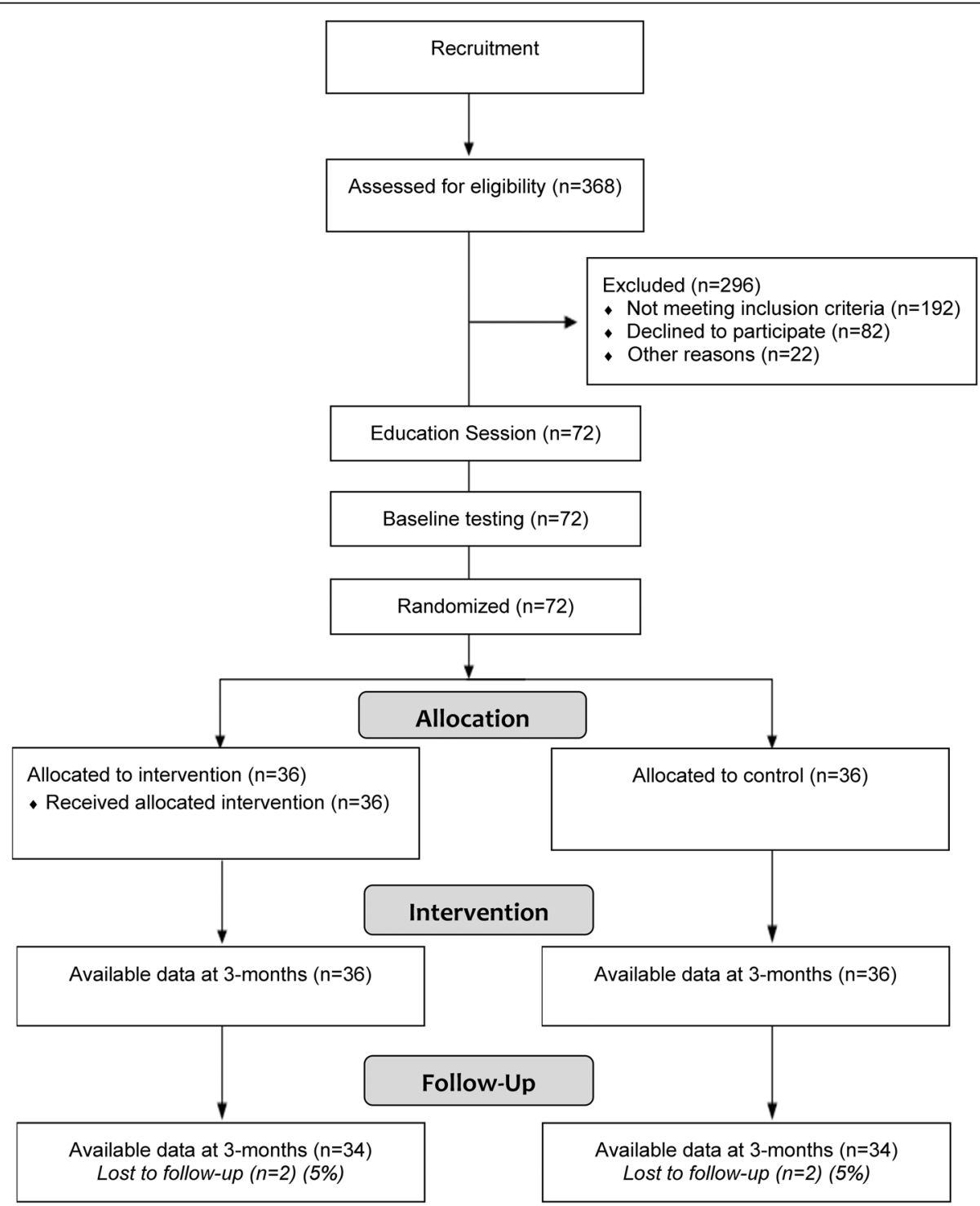

Fig. 1 Flow of study protocol 
disorder; severe mental illness such as psychosis; learning disability; dementia; registered blind; housebound or resident in nursing home; non-ambulant; pregnancy; advanced cancer.

\section{Randomisation and allocation}

Participants who fulfilled the inclusion criteria and consented to take part in the trial were randomly allocated to either the intervention or the control group based on a random number sequence produced by a computer generated program (randomizer.org). Assignments were prepared and sealed in sequentially numbered opaque envelopes. Assignment was made by opening the next envelope in the sequence, after the recruiter had determined eligibility for the study, participants had consented to take part, attendance at an education session was confirmed and baseline measurements were completed.

\section{Procedure}

Participants' characteristics and outcome measures were recorded at baseline, after 3 months of intervention (post-intervention) and at 6 months (follow-up) by assessors blinded to the study group assignment. The extension of outcome measures from baseline to 6 months, which included a 3-month period where no contact with participants was made, was designed to investigate behaviour change maintenance using a previously accepted follow-up duration [31]. A recent systematic review highlighted the need for behaviour change interventions to distinguish between initial behaviour change and behaviour change maintenance [32].

\section{Intervention}

All enrolled participants attended an education session prior to group allocation. The education session was a facilitated learning session based around self-management and lifestyle modification and was carried out using a self-determination theory (SDT) framework [33]. SDT is a general theory of human motivation that defines motivation as "psychological energy directed at a particular goal" [34]. Individuals are more likely to engage in certain behaviours, physical activity for example, if they both value that behaviour, and have motivation for change [34]. SDT was used in this group setting to support, educate and motivate participants around positive lifestyle choices [33].

The intervention group completed a telephone-based, integrated MI-CBT intervention, delivered in eight 30-min sessions over 12 weeks. The intervention was delivered using an MI framework, where MI microskills (open-ended questions, affirmations, reflections and summaries) were used in all sessions to progress participants through the MI processes of change (engagement, focusing, evocation, and planning) [16]. Throughout intervention sessions 1 to 4, MI was predominantly delivered in isolation (i.e., without
CBT), exploring participants' feelings about change and evoking intentions to change [16]. Where MI was used alone, the person delivering the intervention refrained from discussing any specific change-oriented strategies, and instead focused on exploring participant feelings and specific ambivalence regarding barriers to physical activity [16]. In the subsequent sessions, the integrated MI-CBT phase, more specific focus was directed on the identified drivers of ambivalence and resistance, leading to the formulation of goal-directed action plans [16, 35]. The CBT treatment built upon a number of evidence-based protocols with adaptations to focus on the goal of change in PA [35]. The CBT component focused more explicitly on individual determinants of PA such as PA experiences, PA outcome expectations, and PA self-efficacy [35]. The CBT strategies, which included goal setting, action planning, self-monitoring, personal feedback and relapse prevention, were incorporated within this MI framework for supporting PA change and maintenance [36]. The intervention used the integration of MI with CBT in two ways: (i) the underlying spirit of MI was used as a foundational platform from which to conduct $\mathrm{CBT}$, and (ii) during more action orientated sessions therapists could switch back to MI in response to identified markers of ambivalence or resistance $[35,36]$.

The intervention was delivered by an experienced allied health clinician trained in MI-CBT, including workshop attendances, and one-on-one coaching from an experienced practicing psychologist. The intervener's proficiency in using motivational interviewing was confirmed via role-play sessions, one at the commencement and one at midpoint of the intervention. Proficiency was confirmed by an independent assessor using the validated Motivational Interviewing Integrity scale 3.1.1 [37]. The intervener's proficiency in using motivational interviewing was rated as competent on the global clinician rating at both assessments. All participants enrolled into the control arm attended the education session. Apart from contact regarding follow-up outcome measures, participants of the control group received no further contact initiated by the research team.

\section{Outcome measures}

The primary outcome, MVPA (minutes/day) was assessed by accelerometry (wGT3X-BT; Actigraph, USA) during all waking hours over 7 consecutive days. PA was calculated using the manufacturers software (Actilife; Actigraph, USA) with cut points by Freedson Adult (1998) used to provide daily measures of MVPA (> $1951 \mathrm{cpm}$ ) [38]. Accelerometer wear time was based on activity counts per minute. Non-wear time was defined as $60 \mathrm{~min}$ or more of consecutive activity counts of zero, with a spike tolerance of $2 \mathrm{~min}$ and $100 \mathrm{cpm}$. Accelerometer data were considered valid if the accelerometer was worn $>10 \mathrm{~h}$ per day for at least 5 of 7 days including at least 1 weekend day [39]. The 
accelerometer was worn on a waist band, over the right hip. In adults, the hip-mounted ActiGraph has demonstrated high inter-device reliability $(r=0.98)$ and validity against indirect calorimetry $(r=0.56, p<0.001)$ [40]. Participants used logbooks to report significant PA events (e.g., attending exercise class, going for a walk, heavy gardening) and periods of accelerometer non-wear. Participants returned the PA logbook along with the accelerometer within $48 \mathrm{~h}$ of the last accelerometer day. PA data were verified manually against the PA logbooks.

Anthropometric measures were taken objectively in accordance with International Standards for Anthropometric Assessment [41]. Waist circumference (WC) was measured to the nearest $0.1 \mathrm{~cm}$ using a rigid anthropometric measuring tape (Lufkin, US). Body mass was recorded to the nearest $0.1 \mathrm{~kg}$ using a calibrated scale (model 813; Seca, Germany). Free standing stature was recorded to the nearest $0.1 \mathrm{~cm}$ using a calibrated equipment with the participant barefoot (Portable stadiometer; Seca, Germany). Body mass index (BMI) was calculated by dividing body mass by the square of height. Self-efficacy to be physically active was measured using the physical activity self-efficacy survey [42]. The survey measures confidence related to undertaking physical activity over a continual timeframe with a higher score indicating a higher degree of self-efficacy. The survey has support for both its reliability and validity [42]. Health-related quality of life (HrQoL) was measured using the Medical Outcomes Study Short Form 12 Health Survey (SF-12) [43]. The SF-12 is a valid and reliable tool with published psychometric support [44]. A single index score on a scale of 0 to 1 was calculated for all participants, with a higher score indicating a more favourable health state [45].

The Australian type 2 diabetes risk assessment tool (AUSDRISK) was used to measure risk of type 2 diabetes [46]. This 12-item tool has been validated in a number of Australian studies [46]. The AUSDRISK includes questions on age, gender, waist circumference, and family history of diabetes. Potential scores range from 0 to 38 and relate to the probability of developing diabetes within the next 5 years [46]. For scores of $12-15$, approximately one person in every 14 will develop diabetes [46]. For scores of 20 and above, approximately one person in every 3 will develop diabetes [46]. Demographic data were collected on participant postcode, employment status, smoking status and medical history.

\section{Study size}

In order to detect between-group differences of $30 \pm 50$ (mean $\pm \mathrm{SD})$ minutes, the standardized mean difference, or effect size required is 0.60 [47]. A sample size of 30 participants per arm was calculated to be sufficient to detect an effect size of 0.60 or greater, with the alpha set at 0.05 , and the power set at 0.80 . Protecting against a drop-out rate of $20 \%$ over the 6 -month study duration, 36 participants were recruited and randomised into each arm.

\section{Data analyses}

Analyses were carried out using IBM SPSS Statistics for Windows (Version 23.0; IBM Corp., USA) and statistical significance was set at an alpha of 0.05 . Data were assessed for normal distribution by Shapiro-Wilk's [48]. Homogeneity of variances and covariances were assessed by Levene's test and Box's M test, respectively. Grouped data are presented as mean \pm standard deviation. For the main analyses, a series of mixed-model ANOVAs (within: time; between: intervention) were used to assess the effects of the integrated MI-CBT intervention on each of the outcome variables separately. Mauchly's test was consulted and Greenhouse-Geisser correction was applied if the assumption of sphericity was violated [48]. A significant interaction effect was interpreted to demonstrate that the change in dependent variables was influenced by intervention. Where data were in breach of Shapiro-Wilks test of normality, sensitivity analyses were performed. Data were explored for significant outliers and repeat sensitivity analyses were undertaken on data with outliers removed. Repeated sensitivity analyses provided no indication that the outliers had a significant effect on the outcome; therefore, all data were included in analyses.

A full intention-to-treat approach was used. For participants with missing data at 6-month follow-up $(n=2$ in both groups), the last-observation-carried forward approach was adopted [49]. Repeat sensitivity analyses were undertaken on data with and without imputing the last-observation-carried forward value. The repeated sensitivity analyses provided no indication that the imputed values had a significant effect on the outcome.

\section{Results}

A total of 72 participants ( $75 \%$ female) completed their baseline and 3-month assessment, and 68 participants completed the 6-month assessment (Fig. 1). Valid activity monitor data demonstrated wear time per day of 13 $\pm 1.5 \mathrm{~h}$ at baseline, $12 \pm 2.2 \mathrm{~h}$ at 3 months and $13 \pm 1.7 \mathrm{~h}$ at 6 months as calculated by using the manufacturer's software (Choi algorithm) and corroborated through participant log diaries. The participants were $53 \pm 8$ years of age with a mean BMI of $30.8 \mathrm{~kg} / \mathrm{m}^{2}$, and the majority (86\%) had completed either secondary school or tertiary education. At baseline there were statistically significant differences between the groups for MVPA, where the intervention group completed lower daily MVPA than the control group, and for physical activity self-efficacy, where the control group reported higher levels of self-efficacy to be physically active (Table 1). All participants enrolled into the intervention arm received their scheduled eight sessions of integrated MI-CBT. The typical length of each session was $30 \pm 3$ min.

There was a significant group $x$ time interaction indicating that changes in MVPA from baseline through 
Table 1 Characteristics of participants at baseline

\begin{tabular}{|c|c|c|c|c|}
\hline \multirow[t]{2}{*}{ Variable } & Total & Intervention & Control & \multirow[t]{2}{*}{$p$-value } \\
\hline & 72 & 36 & 36 & \\
\hline Age (years) & $53 \pm 8$ & $53 \pm 8$ & $54 \pm 7$ & $0.70^{a}$ \\
\hline Sex: female, n (\%) & $54(75 \%)$ & $28(78 \%)$ & $26(72 \%)$ & $0.58^{a}$ \\
\hline Stature $(\mathrm{cm})$ & $166 \pm 8$ & $165 \pm 9$ & $168 \pm 7$ & $0.20^{a}$ \\
\hline Weight (kg) & $84.9 \pm 9.4$ & $84.5 \pm 9.9$ & $85.3 \pm 8.9$ & $0.72^{a}$ \\
\hline $\mathrm{BMI}\left(\mathrm{kg} / \mathrm{m}^{2}\right)$ & $30.8 \pm 4.1$ & $31.1 \pm 4.0$ & $30.5 \pm 4.2$ & $0.51^{\mathrm{a}}$ \\
\hline MVPA (min/day) & $31.2 \pm 10.1$ & $28.1 \pm 9.9$ & $33.3 \pm 10.3$ & $0.03^{a}$ \\
\hline PA Self-efficacy & $31 \pm 10$ & $28 \pm 8$ & $33 \pm 10$ & $0.05^{a}$ \\
\hline Smoker, n (\%) & $23(32 \%)$ & $12(33 \%)$ & $11(31 \%)$ & $0.80^{b}$ \\
\hline Obesity, n (\%) & $38(53 \%)$ & $22(61 \%)$ & $16(44 \%)$ & $0.16^{b}$ \\
\hline Hypertension, n (\%) & $14(20 \%)$ & $9(25 \%)$ & $5(14 \%)$ & $0.23^{b}$ \\
\hline OA/RA, n (\%) & $27(38 \%)$ & $16(44 \%)$ & $11(31 \%)$ & $0.22^{b}$ \\
\hline Depression/anxiety, n (\%) & $30(42 \%)$ & $16(44 \%)$ & $14(40 \%)$ & $0.63^{b}$ \\
\hline Employment status, n (\%) & & & & $0.43^{b}$ \\
\hline Full time & $22(31 \%)$ & $10(28 \%)$ & $12(33 \%)$ & \\
\hline Part time & $30(42 \%)$ & $18(50 \%)$ & $12(33 \%)$ & \\
\hline Unemployed & $7(10 \%)$ & $4(11 \%)$ & $3(8 \%)$ & \\
\hline Retired & $12(16 \%)$ & $4(11 \%)$ & $8(22 \%)$ & \\
\hline Other & $1(1 \%)$ & 0 & $1(4 \%)$ & \\
\hline Education, n (\%) & & & & $0.47^{b}$ \\
\hline Year 10/11 & $10(14 \%)$ & $4(11 \%)$ & $6(17 \%)$ & \\
\hline Year 12 & $22(31 \%)$ & $12(33 \%)$ & $10(28 \%)$ & \\
\hline Cert I-IV & $18(25 \%)$ & $7(20 \%)$ & $11(30 \%)$ & \\
\hline Diploma & $13(18 \%)$ & $9(25 \%)$ & $4(11 \%)$ & \\
\hline Bachelor or higher & $9(12 \%)$ & $4(11 \%)$ & $5(14 \%)$ & \\
\hline
\end{tabular}

Group data expressed as means \pm standard deviations. Figures in parentheses are proportions. BMI: Body mass index; MVPA: Moderate-to-vigorous physical activity; OA: Osteoarthritis; RA: Rheumatoid arthritis. ${ }^{a}$ t-test between intervention and control groups. ${ }^{b}$ chi square test between intervention and control groups

follow-up differed between intervention groups $(p<0.001$; Fig. 2). The patterns for groups responded differently over time, where the intervention group significantly increased MVPA at post-intervention by $15.3 \mathrm{~min} /$ day $(95 \% \mathrm{CI}: 9.7$ to $21.0 \mathrm{~min} /$ day), and by $12.9 \mathrm{~min} /$ day $(95 \% \mathrm{CI}: 6.5$ to $19.5 \mathrm{~min} /$ day) at follow-up. In contrast, MVPA decreased from baseline to follow-up by $9.9 \mathrm{~min} /$ day $(95 \% \mathrm{CI}:-3.7$ to $-16.0 \mathrm{~min} /$ day) in the control group.

Statistically significant group $\mathrm{x}$ time interaction effects were also found for all secondary outcomes (Table 2). For the intervention group, at follow-up there were significant changes in anthropometrics, resulting in changes in WC $(-2.5 \mathrm{~cm}, 95 \% \mathrm{CI}:-1.8$ to $-3.1 \mathrm{~cm})$, body mass $(-2.7 \mathrm{~kg}$, 95\%CI: -2.1 to $-3.3 \mathrm{~kg})$, and BMI $\left(-1.0 \mathrm{~kg} / \mathrm{m}^{2}, 95 \% \mathrm{CI}:-0.8\right.$ to $-1.2 \mathrm{~kg} / \mathrm{m}^{2}$ ) indicating sustained changes in these variables. Relative to the control group, the intervention groups also demonstrated significant changes in physical activity self-efficacy (10 points, 95\%CI: 6 to 14 points), type 2 diabetes risk ( -1 risk point, $95 \% \mathrm{CI}$ : -1 to 0 risk points) and HrQoL (0.04 units, 95\%CI: 0.01 to 0.07 units).

\section{Discussion}

Integrated MI-CBT resulted in a meaningful increase in MVPA that was maintained at 6 months follow-up in ambulatory secondary care adults. The intervention also resulted in significant improvements in body mass, WC, BMI, PA self-efficacy, type 2 diabetes risk, and HrQoL. These improvements were maintained at 6 -months, indicating a lasting effect of the intervention. This is the first study to demonstrate that an integrated MI-CBT intervention, delivered from a secondary care setting can result in significant changes in behavioural and health-related outcomes.

\section{Changes and maintenance in physical activity}

The Healthy4U trial recruited participants deemed to be insufficiently active via self-report, and seeking to become more physically active. At baseline, daily MVPA was $31 \pm 10 \mathrm{~min}$, indicating moderate levels of PA. All participants completed their baseline measures after attending the education session. Interventions based on SDT have been shown to result in short-term increases 


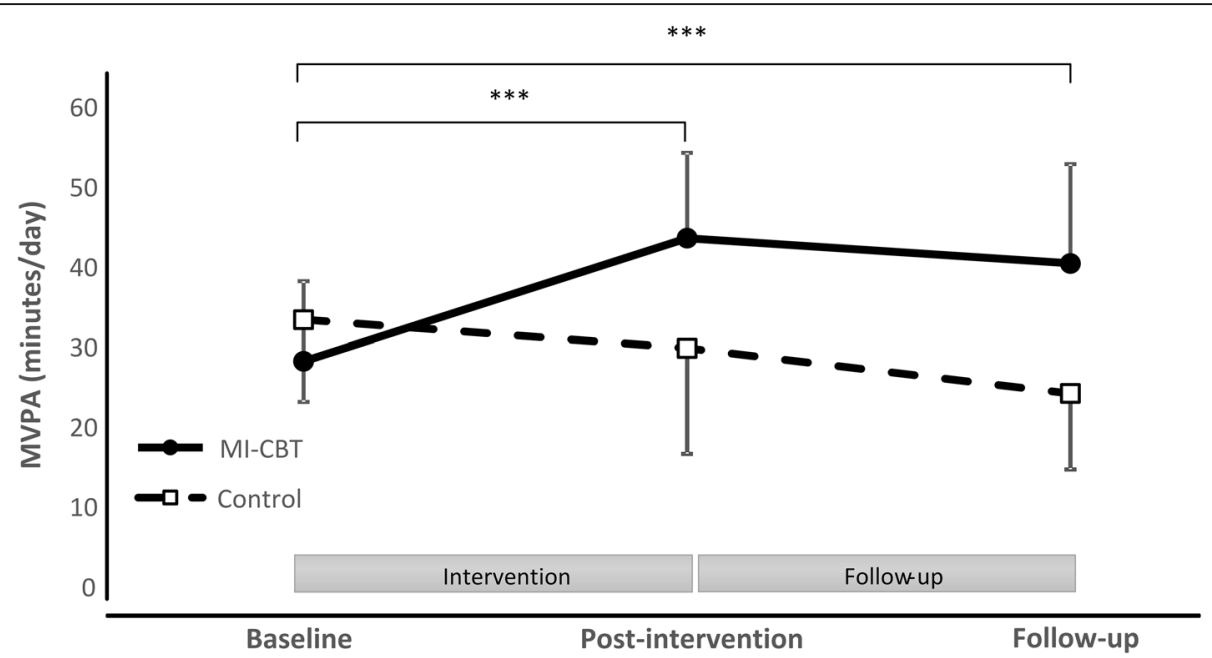

Fig. 2 Minutes per day of moderate-to-vigorous physical activity (MVPA) for the intervention and control groups at baseline, post-intervention and follow-up. *** $p<0.001$

in PA [50]. Therefore, it is likely that the education session contributed to moderate amounts of MVPA across all participants at baseline [50]. Despite the moderate level of PA observed at baseline, the intervention group significantly increased MVPA at 3 months (post-intervention) by a further $15.3 \mathrm{~min} /$ day (95\%CI: 9.7 to $21.0 \mathrm{~min} /$ day), with similar MVPA recorded at follow-up (12.9 $\mathrm{min} /$ day; $95 \% \mathrm{CI}: 6.5$ to $19.5 \mathrm{~min} /$ day). These results indicate a positive change in behaviour that was maintained at 6 months. To put this change into perspective, an additional $15 \mathrm{~min}$ of PA is associated with a reduction in all-cause mortality of $4 \%$, regardless of age [51]. In contrast, compared to baseline, the control group decreased MVPA at follow-up by $9.9 \mathrm{~min} /$ day (95\%CI: -3.7 to $-16.0 \mathrm{~min} /$ day). This reduction in MVPA in the control group is likely to reflect change from an elevated baseline value resulting from the initial education session. Decreases in PA have been shown to occur following the end of an exercise intervention, demonstrating the challenges of implementing prescriptive exercise interventions into the real world [52]. Studies have attempted to address this through the incorporation of self-monitoring strategies to prevent PA recidivism following the completion of exercise interventions [53]. A recent meta-analysis recommended that lifestyle interventions utilise self-help strategies for health related behaviour change [54]. The integration of $\mathrm{MI}$ and $\mathrm{CBT}$ provides strategies for participants to identify and overcome barriers to initiate and maintain behaviour change [20]. The observed changes in MVPA in the intervention group is suggestive of the effectiveness of integrated MI-CBT for PA change and maintenance.

\section{Changes and maintenance in anthropometrics}

Compared to control, integrated MI-CBT resulted in significant changes in anthropometric outcomes. From baseline to follow-up, body mass reduced by $2.7 \mathrm{~kg}$ (95\%CI: -2.1 to $-3.3 \mathrm{~kg})$ in the intervention group. Although the mean reduction in body mass did not exceed a clinically significant value of $5 \%$ [55], weight loss over the duration

Table 2 Means and standard deviations for outcome measures by time and group based on an intent-to-treat analyses

\begin{tabular}{|c|c|c|c|c|c|c|c|c|}
\hline \multirow[t]{2}{*}{ Outcome } & \multicolumn{3}{|c|}{ Intervention } & \multicolumn{3}{|l|}{ Control } & \multicolumn{2}{|l|}{ Analyses } \\
\hline & Baseline & Post-Intervention & $\overline{\text { Follow-up }}$ & Baseline & Post-Intervention & $\overline{\text { Follow-up }}$ & $\begin{array}{l}\text { Time } x \\
\text { Group (F) }\end{array}$ & $\begin{array}{l}\text { Effect } \\
\text { size }^{b}\end{array}$ \\
\hline MVPA (min/day) & $28.1 \pm 9.9$ & $43.5 \pm 10.7$ & $41.1 \pm 12.5$ & $33.3 \pm 10.3$ & $29.8 \pm 13.2$ & $23.4 \pm 9.7$ & $23.25^{*}$ & 0.249 \\
\hline Waist circumference $(\mathrm{cm})$ & $99.3 \pm 11.7$ & $97.2 \pm 11.4$ & $96.8 \pm 11.3$ & $96.9 \pm 11.5$ & $97.2 \pm 11.4$ & $97.3 \pm 11.3$ & $61.84^{*}$ & 0.469 \\
\hline Body mass (kg) & $84.5 \pm 9.9$ & $82.5 \pm 9.6$ & $81.7 \pm 9.4$ & $85.3 \pm 8.9$ & $85.6 \pm 8.8$ & $85.7 \pm 8.7$ & $70.04^{*}$ & 0.500 \\
\hline BMI $\left(\mathrm{kg} / \mathrm{m}^{2}\right)$ & $31.1 \pm 4.0$ & $30.4 \pm 4.0$ & $30.1 \pm 3.9$ & $30.5 \pm 4.2$ & $30.6 \pm 4.1$ & $30.7 \pm 4.1$ & $71.31^{*}$ & 0.505 \\
\hline PA self-efficacy (Risk score) & $28 \pm 8$ & $36 \pm 7$ & $38 \pm 7$ & $34 \pm 11$ & $33 \pm 10$ & $32 \pm 6$ & $18.72^{*}$ & 0.211 \\
\hline HrQoL (Scale) & $0.63 \pm 0.08$ & $0.62 \pm 0.08$ & $0.67 \pm 0.09$ & $0.65 \pm 0.07$ & $0.65 \pm 0.08$ & $0.62 \pm 0.05$ & $18.08^{*}$ & 0.205 \\
\hline Type 2 diabetes risk (Risk score) & $14 \pm 5$ & $13 \pm 4$ & $13 \pm 4$ & $14 \pm 5$ & $14 \pm 5$ & $14 \pm 5$ & $10.91^{*}$ & 0.135 \\
\hline
\end{tabular}

Group data are means \pm standard deviations. MVPA moderate-to-vigorous physical activity, BMI Body mass index, HrQoL Health-related quality of life. ${ }^{*} p<0.001 .{ }^{a}$ interaction effect of time by group on dependent variable; ${ }^{b}$ Partial eta-squared 
of the study is noteworthy as most middle aged individuals continue to gain weight each year [56]. The average gain in body mass of $0.5 \mathrm{~kg}$ (95\% CI: -0.3 to 1.0$)$ in the control exemplified the normal pattern of middle-aged weight gain [56]. The $2.5 \mathrm{~cm}$ decrease in $\mathrm{WC}$ observed in the MI-CBT group ( $95 \% \mathrm{CI}:-1.8$ to $-3.1 \mathrm{~cm}$ ) is also promising, as the baseline value of mean WC suggest an increased risk of obesity related diseases [57]. There is limited evidence for what constitutes a minimally important change in WC; however, a change of between 1.8 and $4.1 \mathrm{~cm}$ has been proposed as a marker of maintained change [58]. Furthermore, high waist circumference is positively associated with higher mortality rates at all levels of BMI from 20 to $50 \mathrm{~kg} / \mathrm{m}^{2}$ [59]. A meta-regression analysis found that a $1 \mathrm{~cm}$ increase in WC can increase the relative risk of cardiovascular events by $2 \%$ [60]. The observed decrease in WC in this study is in contrast with longitudinal data on Australian adults, which reported an annualised increase in waist circumference, that did not slow over time [61]. The observed pattern of increased WC occurred with a simultaneous decrease in body mass over the period [61]. NHANES data also indicated that over time WC increased to a larger extent that expected, relative to changes in body mass over the same period [62]. These findings suggest that excess body weight over time is resulting in an increase in central adiposity, which is associated with a greater risk of cardiometabolic diseases [62]. Although recruitment into this study was based upon changing PA, not body composition, the positive changes in anthropometric measures are of clinical importance as these risk factors are strong indicators of metabolic dysfunction, and associated with development and worsening of cardiovascular disease and diabetes [63]. The changes in both WC and body mass found in this study may strengthen confidence in the MI-CBT intervention for change and maintenance in anthropometric measures.

\section{Changes and maintenance in health-related outcomes}

The average baseline scores for PA self-efficacy indicated that the sample had moderate belief in their ability to be physically active. Lack of confidence and self-belief are strongly associated with low rates of PA [64]. Despite having had higher levels of PA self-efficacy at baseline, the mean PA self-efficacy in the control group decreased at post-intervention and even further at follow-up, which diametrically opposed the trajectory of the intervention group. This increase in PA self-efficacy is a potential mediator for the improvement and maintenance in PA levels among the intervention group. The contrast in patterns of PA self-efficacy between the groups might be explained by the exposure of the intervention group to the MI-CBT treatment. MI-CBT strategies focus on increasing self-efficacy for behaviour change, as well as developing strategies for planning and relapse prevention
$[16,20]$. The changes in self-efficacy found in the study participants exhibited the same pattern of change as PA. The integrated MI-CBT group increased their self-efficacy and PA, while the control group demonstrated decreases in these outcomes.

Integrated MI-CBT resulted in small but significant changes in type 2 diabetes risk. The mean baseline AUSDRISK score of 14 indicates that participants are at high risk of developing type 2 diabetes within 5 years [46]. Early screening for 2 diabetes risk, and subsequent lifestyle modification reduces the risk of type 2 diabetes and other chronic diseases [65]. Research indicates that almost 40\% of individuals with prediabetes, if left untreated, will progress to diabetes in 4 years [66]. Lifestyle interventions can decrease the percentage of those with prediabetes who go on to develop diabetes to $20 \%$ [66]. The observed increase in PA and reduction in WC in the intervention group contributed to a reduction in risk score, whereas no change in risk score was observed in the control group. At follow-up the intervention group had a mean risk score of 13 , which still indicates a high risk developing type 2 diabetes [46]. The long-term maintenance of behaviour change is important for the effectiveness of lifestyle interventions to prevent type 2 diabetes.

The integrated MI-CBT intervention also resulted in small but significant changes between the groups for HrQoL. A consistent positive association has been demonstrated between PA and HrQoL [67]. Changes in HrQoL in the intervention group were significant at follow-up, but not at post-intervention. Changes in multidimensional quality of life measures have been shown to be less responsive than measures of specific patient outcomes, in this example PA change, particularly where interventions are aimed at achieving a particular outcome [68]. This might account for the slower degree of change in HrQoL exhibited by the intervention group [68].

\section{Strengths}

This study was unique in that it enrolled participants from secondary care in a public hospital, integrating preventative health into secondary care. Patients presenting to secondary care have higher rates of chronic disease than the general population, and the targeting of high risk groups is essential to address the rising prevalence of chronic diseases in Australia [69]. While hospital patients have expressed a desire for health behaviour interventions [5], research from practicing hospitals doctors indicate that they do not have sufficient time to spend giving preventive advice to patients [27]. The Healthy4U intervention was implemented to address this identified gap, to supplement clinical practice in secondary care, facilitating a process where clinicians under time duress were able to direct patients into a health behaviour intervention. With rates of lifestyle related disease 
projected to continue to rise in the future it is important to develop and evaluate innovative ways to address this concern [70]. For a regional hospital the delivery of the health coaching via telephone was important as it can extend reach to both geographically and socially disadvantaged areas, which commonly have higher risk of chronic diseases [71]. In RCT's on behaviour change, the maintenance of physical activity behaviour change is not often reported, influencing the generalisability of findings [31]. The Healthy4U trial was purposely designed to assess the effect of the intervention for behaviour change and maintenance by extending outcome measures to 6 months from baseline. The use of objectively measured PA at all time points was a considerable strength of the study. Objective measures offer more precise estimates of activity intensity while removing many of the issues associated with participant recall and response bias [72]. A recent meta-analysis on MI for PA change demonstrated that the effect size of the intervention was smaller in trials using objective measures, relative to self-reported data [73]. The objectively measured changes in PA strengthen the confidence in the findings [72].

The participant retention rate in this study was high, with only 4 participants (2 from both groups) lost at follow-up. All participants were required to attend the education session, which was designed to motivate behavioural change. Mandatory attendance at the education session might have positively influenced participation in the study for individuals allocated to both groups. This study used a Manual of Operating Procedures (MOP) to facilitate consistency in protocol implementation and data collection across participants. The MOP transformed the study protocol into a guideline describing the procedure for initial and subsequent contacts with participants. The MOP included standardised procedures for reminding participants of their upcoming commitments in relation to attendance for assessments and accelerometer use, which might partially explain the strong compliance rates.

Intervention adherence rate was also high, with $100 \%$ of participants receiving all eight sessions of integrated MI-CBT. Intervention-led health behaviour change relies on mutual understanding and trust between the intervener and the participant, which can only emerge when sufficient time is given [74]. The individual delivering the intervention was confirmed as being fidelity proficient.

\section{Limitations}

Although the target number of participants was modest, the sample size was large enough to detect significant differences between groups in all outcome measures. Recruitment of volunteers into this study meant that all participants were already interested in becoming more active. Although this might limit the transferability of findings to all community-dwelling adults, it does not influence interpretation about the effectiveness of the intervention when compared against the control, due to the robust nature of the RCT study design. As the study was confined to a 6-month timeframe, it is not clear if improvements were sustained beyond that measurement point. Nevertheless the intervention resulted in increases in MVPA that were sustained at follow-up, which is indicative of behaviour change maintenance [31], and the exhibited patterns of behaviour change found in the outcomes were not indicative of recidivism following the intervention completion [75]. Lastly, the broad generalizability of these findings might be difficult because the study was conducted in one regional location and the majority of participants were female and obese.

\section{Conclusion}

Due to the increased prevalence of chronic disease, addressing the lifestyle behavioural mediators of these preventable diseases is essential. The Healthy $4 \mathrm{U}$ trial demonstrates that, in comparison to control, integrated MI-CBT resulted in significant improvements in PA, anthropometrics, self-efficacy, type 2 diabetes risk and HrQoL, which were maintained at follow-up. These findings demonstrate that a behaviour change intervention implemented in secondary care is effective for the prevention and management of chronic disease.

\section{Abbreviations \\ ANOVA: Analysis of Variance; BMI: Body Mass Index; CBT: Cognitive Behaviour Therapy; Cl: Confidence Interval; HrQoL: Health- Related Quality of Life; MI: Motivational Interviewing; MI-CBT: Integrated MI and CBT; \\ MVPA: Moderate-to-Vigorous Physical Activity; NHANES: The National Health and Nutrition Examination Survey; PA: Physical Activity; RCT: Randomised Controlled Trial; SD: Standard Deviation; SDT: Self-Determination Theory; SF- \\ 12: Medical Outcomes Study Short Form 12 Health Survey; WC: Waist Circumference}

Acknowledgements

The authors would like to thank all participants for taking part in the study.

Availability of data and materials

The dataset used and analysed during the current study are available from the corresponding author on reasonable request.

\section{Authors' contributions}

$\mathrm{SB}^{1}, \mathrm{MK}, \mathrm{SB}^{2}$ and $\mathrm{PO}^{\prime} \mathrm{H}$ conceived the project and assisted with the protocol design. $\mathrm{SB}^{1}$ managed the trial including recruitment and data collection, coordinated the intervention program, performed statistical analysis, and drafted the manuscript. $\mathrm{PO}^{\prime} \mathrm{H}$ provided training in the intervention. $\mathrm{SB}^{1}$ and MK interpreted the data and drafted the manuscript. All authors read, edited and approved the final manuscript.

Ethics approval and consent to participate

The study was approved by the Research Ethics Committees of Bendigo Health Care group (approved September 16, 2016; reference number LNR/ 16/BHCG/42) and La Trobe University College of Science Health and Engineering Human Ethics Sub-Committee (approved October 3, 2016). Written informed consent was obtained from all participants before they join the study.

Consent for publication

Not applicable. 


\section{Competing interests}

The authors declare they have no competing interests.

\section{Publisher's Note}

Springer Nature remains neutral with regard to jurisdictional claims in published maps and institutional affiliations.

\section{Author details}

'La Trobe University, La Trobe Rural Health School, PO Box 199, Bendigo, VIC 3552, Australia. ${ }^{2}$ La Trobe University, School of Psychology and Public Health, Bundoora, VIC 3068, Australia.

\section{Received: 30 June 2018 Accepted: 24 September 2018}

\section{Published online: 11 October 2018}

\section{References}

1. Bodenheimer T, Lorig K, Holman H, Grumbach K. Patient self-management of chronic disease in primary care. JAMA. 2002;288:2469-75.

2. Britt HC, Harrison CM, Miller GC, Knox SA. Prevalence and patterns of multimorbidity in Australia. Med J Aust. 2008;189:72-7.

3. Groene O, Alonso J, Klazinga N. Development and validation of the WHO self-assessment tool for health promotion in hospitals: results of a study in 38 hospitals in eight countries. Health Promot Int. 2010:25:221-9.

4. West R, McNeill A, Raw M. Smoking cessation guidelines for health professionals: an update. Thorax. 2000:55:987-99.

5. Leijon ME, Stark-Ekman D, Nilsen P, Ekberg K, Walter L, Ståhle A, Bendtsen P. Is there a demand for physical activity interventions provided by the health care sector? Findings from a population survey. BMC Public Health. 2010;10:34.

6. Schoen C, Osborn R, Huynh PT, Doty M, Zapert K, Peugh J, Davis K. Taking the pulse of health care systems: experiences of patients with health problems in six countries. Health Aff (Millwood) 2005; Suppl Web Exclusives:W5-509-525.

7. Warburton DE, Nicol CW, Bredin SS. Health benefits of physical activity: the evidence. CMAJ. 2006;174:801-9.

8. Orozco L, Buchleitner AM, Gimenez-Perez G, Roque IFM, Richter B, Mauricio D. Exercise or exercise and diet for preventing type 2 diabetes mellitus. Cochrane Database Syst Rev. 2008:CD003054.

9. Shaw K, Gennat H, O'Rourke P, Del Mar C. Exercise for overweight or obesity. Cochrane Database Syst Rev 2006:CD003817.

10. Williams MA, Haskell WL, Ades PA, Amsterdam EA, Bittner V, Franklin BA, Gulanick M, Laing ST, Stewart KJ, American Heart Association Council on clinical C, et al. Resistance exercise in individuals with and without cardiovascular disease: 2007 update: a scientific statement from the American Heart Association Council on clinical cardiology and council on nutrition, physical activity, and metabolism. Circulation. 2007;116:572-84.

11. Lollgen H, Bockenhoff A, Knapp G. Physical activity and all-cause mortality: an updated meta-analysis with different intensity categories. Int I Sports Med. 2009;30:213-24.

12. Eakin EG, Brown WJ, Marshall AL, Mummery K, Larsen E. Physical activity promotion in primary care: bridging the gap between research and practice. Am J Prev Med. 2004;27:297-303.

13. Valkenet K, IGvd P, Dronkers JJ, WRd V, Lindeman E, Backx FJ. The effects of preoperative exercise therapy on postoperative outcome: a systematic review. Clin Rehabil. 2011;25:99-111.

14. Nigg CR, Borrelli B, Maddock J, Dishman RK. A theory of physical activity maintenance. Appl Psychol. 2008;57:544-60.

15. Teeter BS, Kavookjian J. Telephone-based motivational interviewing for medication adherence: a systematic review. Translational Behavioral Medicine. 2014:4:372-81.

16. Miller WR, Rollnick S. Motivational interviewing : helping people change. 3rd ed. New York, NY: Guilford Press; 2013.

17. Burke BL, Arkowitz H, Menchola M. The efficacy of motivational interviewing: a meta-analysis of controlled clinical trials. J Consult Clin Psychol. 2003;71:843.

18. Hettema J, Steele J, Miller WR. Motivational interviewing. Annu Rev Clin Psychol. 2005;1:91-111.

19. Westra HA. Managing resistance in cognitive behavioural therapy: the application of motivational interviewing in mixed anxiety and depression. Cogn Behav Ther. 2004;33:161-75.

20. Naar-King S, Earnshaw P, Breckon J. Toward a universal maintenance intervention: integrating cognitive behavioral treatment with motivational interviewing for maintenance of behavior change. J Cogn Psychother. 2013; 27:126-37.

21. Groeneveld IF, Proper KI, van der Beek AJ, Hildebrandt VH, van Mechelen W. Short and long term effects of a lifestyle intervention for construction workers at risk for cardiovascular disease: a randomized controlled trial. BMC Public Health. 2011;11:836.

22. Knittle K, De Gucht V, Hurkmans E, Peeters A, Ronday K, Maes S, Vlieland TV. Targeting motivation and self-regulation to increase physical activity among patients with rheumatoid arthritis: a randomised controlled trial. Clin Rheumatol. 2015:34:231-8.

23. Murphy BM, Worcester MU, Higgins RO, Elliott PC, Le Grande MR, Mitchell F, Navaratnam H, Turner A, Grigg L, Tatoulis J, Goble AJ. Reduction in 2-year recurrent risk score and improved behavioral outcomes after participation in the "beating heart problems" self-management program: results of a randomized controlled trial. J Cardiopulm Rehabil Prev. 2013:33:220-8.

24. Troiano RP, Berrigan D, Dodd KW, Masse LC, Tilert T, McDowell M. Physical activity in the United States measured by accelerometer. Med Sci Sports Exerc. 2008:40:181-8.

25. Hernandez C, Jansa M, Vidal M, Nuñez M, Bertran MJ, Garcia-Aymerich J, Roca J. The burden of chronic disorders on hospital admissions prompts the need for new modalities of care: a cross-sectional analysis in a tertiary hospital. QJM: Int Jour Med. 2009;102:193-202.

26. Borjesson M. Promotion of physical activity in the hospital setting. Dtsch Z Sportmed. 2013;64:162-5.

27. Himmelmann L, Weinehall L. Preventive medical work is important but difficult. Shortage of time and information is main obstacle. Lakartidningen. 1996;93:694-9.

28. Schulz KF, Altman DG, Moher D. CONSORT 2010 statement: updated guidelines for reporting parallel group randomised trials. BMC Med. 2010;8:18.

29. Nelson ME, Rejeski WJ, Blair SN, Duncan PW, Judge JO, King AC, Macera CA, Castaneda-Sceppa C. American College of Sports M, American heart a. physical activity and public health in older adults: recommendation from the American College of Sports Medicine and the American Heart Association. Circulation. 2007;116:1094-105.

30. Rose $S B$, Elley CR, Lawton BA, Dowell AC. A single question reliably identifies physically inactive women in primary care. NZ Med J. 2008;121:U2897.

31. Fjeldsoe B, Neuhaus M, Winkler E, Eakin E. Systematic review of maintenance of behavior change following physical activity and dietary interventions. Health Psychol. 2011;30:99.

32. Kwasnicka D, Dombrowski SU, White M, Sniehotta F. Theoretical explanations for maintenance of behaviour change: a systematic review of behaviour theories. Health Psychol Rev. 2016;10:277-96.

33. Vansteenkiste M, Sheldon KM. There's nothing more practical than a good theory: integrating motivational interviewing and self-determination theory. Br J Clin Psychol. 2006;45:63-82.

34. Ng JY, Ntoumanis N, Thøgersen-Ntoumani C, Deci EL, Ryan RM, Duda JL, Williams GC. Self-determination theory applied to health contexts: a metaanalysis. Perspect Psychol Sci. 2012;7:325-40.

35. Borkovec TD, Costello E. Efficacy of applied relaxation and cognitivebehavioral therapy in the treatment of generalized anxiety disorder. J Consult Clin Psychol. 1993;61:611-9.

36. Craske MG, Barlow DH. Mastery of your anxiety and worry: Oxford University Press; 2006.

37. Moyers T, Martin T, Manuel J, Miller W, Ernst D. Revised global scales: Motivational interviewing treatment integrity 3.1. 1 (MITI 3.1. 1). Unpublished manuscript, University of New Mexico, Albuquerque, NM. 2010.

38. Freedson PS, Melanson E, Sirard J. Calibration of the computer science and applications, Inc. accelerometer. Med Sci Sports Exerc. 1998;30:777-81.

39. Esliger DW, Copeland JL, Barnes JD, Tremblay MS. Standardizing and optimizing the use of accelerometer data for free-living physical activity monitoring. J Phys Act Health. 2005;(3):366-83.

40. Hills AP, Mokhtar N, Byrne NM. Assessment of physical activity and energy expenditure: an overview of objective measures. Front Nut. 2014;1:5.

41. Stewart A, Marfell-Jones M, Olds T, De Ridder J: International standards for anthropometric assessment. 2011.

42. Sallis JF, Pinski RB, Grossman RM, Patterson TL, Nader PR. The development of self-efficacy scales for healthrelated diet and exercise behaviors. Health Educat Res. 1988:3:283-92.

43. Ware JE, Kosinski M, Keller SD. A 12-item short-form health survey: construction of scales and preliminary tests of reliability and validity. Med Care. 1996;34:220-33. 
44. Sanderson K, Andrews G. The SF-12 in the Australian population: crossvalidation of item selection. Aust N Z J Public Health. 2002;26:343-5.

45. Brazier J, Roberts J, Deverill M. The estimation of a preference-based measure of health from the SF-36. J Health Econ. 2002;21:271-92.

46. Chen L, Magliano DJ, Balkau B, Colagiuri S, Zimmet PZ, Tonkin AM, Mitchell P, Phillips PJ, Shaw JE. AUSDRISK: an Australian type 2 diabetes risk assessment tool based on demographic, lifestyle and simple anthropometric measures. Med J Aust. 2010;192:197-202.

47. Wilcox S, Dowda M, Leviton LC, Bartlett-Prescott J, Bazzarre T, CampbellVoytal K, Carpenter RA, Castro CM, Dowdy D, Dunn AL, et al. Active for life. final results from the translation of two physical activity programs Am J Prev Med. 2008;35:340-51.

48. Meyers LS, Gamst G, Guarino AJ. Applied multivariate research: design and interpretation: Sage; 2006.

49. Shao J, Zhong B. Last observation carry-forward and last observation analysis. Stat Med. 2003;22:2429-41.

50. Teixeira PJ, Carraça EV, Markland D, Silva MN, Ryan RM. Exercise, physical activity, and self-determination theory: a systematic review. Int J Behav Nut Phys Act. 2012;9:78.

51. Wen CP, Wai JP, Tsai MK, Yang YC, Cheng TY, Lee MC, Chan HT, Tsao CK, Tsai SP, Wu X. Minimum amount of physical activity for reduced mortality and extended life expectancy: a prospective cohort study. Lancet. 2011;378:1244-53.

52. McNeil J, Farris MS, Ruan Y, Merry H, Lynch BM, Matthews CE, Courneya KS, Friedenreich CM. Effects of prescribed aerobic exercise volume on physical activity and sedentary time in postmenopausal women: a randomized controlled trial. Int J Behav Nut Phys Act. 2018;15:27.

53. Opdenacker J, Delecluse C, Boen F. A 2-year follow-up of a lifestyle physical activity versus a structured exercise intervention in older adults. J Am Geriatr Soc. 2011;59:1602-11.

54. Hartmann-Boye J, Jebb SA, Fletcher BR, Aveyard P. Self-help for weight loss in overweight and obese adults: systematic review and meta-analysis. Am J Public Health. 2015;105:e43-57.

55. Swift DL, Johannsen NM, Lavie CJ, Earnest CP, Blair SN, Church TS. Effects of clinically significant weight loss with exercise training on insulin resistance and Cardiometabolic adaptations. Obesity. 2016;24:812-9.

56. Williamson DF. Weight change in middle-aged Americans. Am J Prev Med. 2004;27:81-2.

57. Zhu S, Wang Z, Heshka S, Heo M, Faith MS, Heymsfield SB. Waist circumference and obesity-associated risk factors among whites in the third National Health and nutrition examination survey: clinical action thresholds. Am J Clin Nutr. 2002;76:743-9.

58. Verweij $L M$, Terwee $C B$, Proper $K I$, Hulshof $C T$, van Mechelen W. Measurement error of waist circumference: gaps in knowledge. Public Health Nutr. 2013;16:281-8.

59. Cerhan JR, Moore SC, Jacobs EJ, Kitahara CM, Rosenberg PS, et al. A pooled analysis of waist circumference and mortality in 650,000 adults. Mayo Clin Proc. 2014;89:335-45.

60. de Koning L, Merchant AT, Pogue J, Anand SS. Waist circumference and waist-to-hip ratio as predictors of cardiovascular events: meta-regression analysis of prospective studies. Eur Heart J. 2007;28:850-6.

61. Peeters A, Magliano DJ, Backholer K, Zimmet P, Shaw JE. Changes in the rates of weight and waist circumference gain in Australian adults over time: a longitudinal cohort study. BMJ Open. 2014;4:e003667.

62. Walls HL, Stevenson CE, Mannan HR, Abdullah A, Reid CM, McNeil JJ, Peeters A. Comparing trends in BMI and waist circumference. Obesity. 2011;19:216-9.

63. Palaniappan L, Carnethon MR, Wang Y, Hanley AJ, Fortmann SP, Haffner SM, Wagenknecht L. Predictors of the incident metabolic syndrome in adults: the insulin resistance atherosclerosis study. Diabetes Care. 2004;27:788-93.

64. Trost SG, Owen N, Bauman AE, Sallis JF, Brown W. Correlates of adults' participation in physical activity: review and update. Med Sci Sports Exerc. 2002:34:1996-2001.

65. Blackford K, Jancey J, Lee AH, James AP, Howat P, Hills AP, Anderson A. A randomised controlled trial of a physical activity and nutrition program targeting middle-aged adults at risk of metabolic syndrome in a disadvantaged rural community. BMC Public Health. 2015;15:284.

66. Tuso P. Prediabetes and lifestyle modification: time to prevent a preventable disease. Perm J. 2014;18:88-93.

67. Penedo FJ, Dahn JR. Exercise and well-being: a review of mental and physical health benefits associated with physical activity. Curr Opin Psychiatry. 2005;18:189-93.
68. Higginson IJ, Carr AJ. Using quality of life measures in the clinical setting. BMJ. 2001;322:1297-300

69. Haby MM, Markwick A, Peeters A, Shaw J, Vos T. Future predictions of body mass index and overweight prevalence in Australia, 2005-2025. Health Promo Int. 2011;27:250-60.

70. Rowley WR, Bezold C, Arikan Y, Byrne E, Krohe S. Diabetes 2030: insights from yesterday, today, and future trends. Popul Health Manag. 2017;20:6-12.

71. O'Hara BJ, Phongsavan P, Venugopal K, Bauman AE. Characteristics of participants in Australia's get healthy telephone-based lifestyle information and coaching service: reaching disadvantaged communities and those most at need. Health Educ Res. 2011:26:1097-106.

72. Prince SA, Adamo KB, Hamel ME, Hardt J, Gorber SC, Tremblay M. A comparison of direct versus self-report measures for assessing physical activity in adults: a systematic review. Int J Behav Nut Phys Act. 2008;5:56.

73. O'Halloran PD, Blackstock F, Shields N, Holland A, lles R, Kingsley M, Bernhardt J, Lannin N, Morris ME, Taylor NF. Motivational interviewing to increase physical activity in people with chronic health conditions: a systematic review and meta-analysis. Clin Rehabil. 2014;28:1159-71.

74. Sjöling M, Lundberg K, Englund $E$, Westman A, Jong MC. Effectiveness of motivational interviewing and physical activity on prescription on leisure exercise time in subjects suffering from mild to moderate hypertension. BMC Research Notes. 2011;4:352.

75. Bassi N, Karagodin I, Wang S, Vassallo P, Priyanath A, Massaro E, Stone NJ. Lifestyle modification for metabolic syndrome: a systematic review. Am J Med 127. 1242;e1210:e1241-2.

\section{Ready to submit your research? Choose BMC and benefit from:}

- fast, convenient online submission

- thorough peer review by experienced researchers in your field

- rapid publication on acceptance

- support for research data, including large and complex data types

- gold Open Access which fosters wider collaboration and increased citations

- maximum visibility for your research: over $100 \mathrm{M}$ website views per year

At BMC, research is always in progress.

Learn more biomedcentral.com/submissions 